\title{
Psychosocial and Economic Evaluation of Stroke Management in the Elderly: A Prospective Study at the Neurology Department in a Hospital in Dakar, Senegal
}

\author{
Diop Cheikh Tacko ${ }^{1,}$, , Gueye Boubacar ${ }^{1}$, Ba Massamba $^{2}$, Coume Mamadou $^{2}$, Ka Ousseynou ${ }^{1}$, \\ Acray Petronille ${ }^{3}$, Faye Adama ${ }^{2}$ \\ ${ }^{1}$ Faculty of Community Health, Alioune Dipo University, Bambey, Senegal \\ ${ }^{2}$ Faculty of Medicine, Pharmacy and Dentistry, Cheikh Anta Dipo University, Dakar, Senegal \\ ${ }^{3}$ Faculty of Medicine, Pharmacy and Dentistry, Abidjan University, Ivory Cost
}

Email address:

cheikhtackodiop@gmail.com (D. C. Tacko)

${ }^{*}$ Corresponding author

\section{To cite this article:}

Diop Cheikh Tacko, Gueye Boubacar, Ba Massamba, Coume Mamadou, Ka Ousseynou, Acray Petronille, Faye Adama. Psychosocial and Economic Evaluation of Stroke Management in the Elderly: A Prospective Study at the Neurology Department in a Hospital in Dakar, Senegal. International Journal of Health Economics and Policy. Vol. 6, No. 2, 2021, pp. 38-43. doi: 10.11648/j.hep.20210602.11

Received: April 5, 2021; Accepted: April 19, 2021; Published: April 29, 2021

\begin{abstract}
Stroke is the second leading cause of death worldwide and the leading cause of physical disability in the elderly. The objective of the study was to evaluate the psychosocial and economic aspects of its management. We conducted a crosssectional, descriptive and evaluative study at the neuroscience clinic of FANN National University Hospital from May 8 to August 8, 2019. It involved 60 people aged 60 years and over received in consultation as well as 59 family caregivers who gave their consent. The caregivers' suffering was evaluated using the MINI ZARIT grid consisting of 5 items for a total score ranging from 0 to 7 . The psychological impact of the disease was evaluated by the Geriatric Depression Scale in its short version (GDS); composed of 15 items scored from 0 to 1 . The direct and indirect financial cost was evaluated on two items: The estimated financial loss associated with the work stoppage estimated by the daily earnings of the primary caregiver. Travel costs related to transportation from home to the neurovascular consultation unit. The mean age of our patients was 71.46 years (standard deviation 7.79 years). Females predominated with a sex ratio of 0.71 . Most of our patients were polygamous $(38.30 \%)$, followed by widowers (35\%). Most of the patients had attended Koranic school (38.30\%) and 31.70\% were illiterate. They were unemployed for $55 \%$. Caregiver burden was absent to mild in $32.20 \%$, mild to moderate in $45.80 \%$ and moderate to severe in $22 \%$. Signs of depression were present in $10 \%$ of patients, the $30 \%$ had a high probability of depression while $60 \%$ of patients had no depression. The average length of time the main caregiver was off work was 23.86 days (standard deviation 64.53 days). The average cost of financial losses related to this work stoppage was 200.38 USD (standard deviation 564.72 USD). The average cost of travel was $\$ 139.24$ (SD \$321.03). The average total cost was \$339.62 (SD \$650.97). The indirect cost of stroke remains quite high and represents a heavy burden for a population where the majority is unemployed, so it is important to propose a psychological support program more adapted to the Senegalese population. The establishment of lowcost home help services and a training program in neuropsychology for clinicians will be useful.
\end{abstract}

Keywords: Stroke, Depression, Cost, Senegal

\section{Introduction}

Senegal, like other African countries, will not be spared from population aging since the demographic growth of the elderly $(3.5 \%)$ exceeds the national growth rate $(2.7 \%)$ [1].
This aging of the population is accompanied by an epidemiological transition characterized by the persistence of communicable diseases and the emergence of new so-called chronic diseases, the growth of which is favored by changes in dietary behavior and lifestyle habits [2].

These chronic diseases in Senegal are dominated by 
cardiovascular diseases (CVD), with arterial hypertension $(\mathrm{AH})$ at the top of the list, causing cardiovascular events such as ischemic stroke (ISA) or hemorrhagic stroke (HSA), myocardial infarction, nephro-angiosclerosis, etc. [3].

Stroke is the second leading cause of death worldwide and the leading cause of physical disability in adults. The increase in its prevalence is therefore parallel to the increase in the number of elderly people [4].

According to the WHO, in 2010, the incidence of stroke in the world is 17 million. It is the second leading cause of death in the world with 6 million per year. An estimated 102 million years of life are lost due to residual disability or death from stroke. Low- and middle-income countries were particularly affected with $68.6 \%$ of new stroke cases, $70.9 \%$ of stroke deaths, and $77.7 \%$ of years of life lost due to disability or death [5].

In Africa, access to care is difficult for the elderly and the overall management of stroke is cumbersome and costly. It is an emergency that requires immediate management. It requires rapid recognition of the signs, urgent transport of the affected individual, effective reaction by the caregiving staff, and monitoring of the disability and possible complications and sequelae. All these steps require human and financial resources. Knowledge of these steps should allow for the development of a good strategy of care and psycho-affective support.

However, few studies have been done in our region to evaluate the cost of managing these conditions; few have focused on the costs related to the psychological, social, and economic aspects of managing the elderly person with a stroke.

The objective of our study is to evaluate the psychosocial and economic aspects of the management of strokes in the elderly at the neuroscience clinic of FANN NUHC. This will involve: describing the sociodemographic characteristics of patients and primary caregivers, assessing the burden of primary caregivers, assessing the psychological impact of stroke on the patient, including depression, and assessing the indirect financial burden of care by the family and the patient.

\section{Methodology}

\subsection{Study Setting}

Our study took place at the neuroscience clinic, which is the national and sub-regional reference center for the management of medical pathologies of the nervous system. It is the second medical service of the National University Hospital of FANN after the psychiatry service. It has a triple mission of care, training and research.

\subsection{Type of Study}

This is a cross-sectional, descriptive and evaluative study.

\subsection{Study Period}

It took place over a four-month period from May to August 2019.

\subsection{Study Population}

It targeted elderly people aged 60 years and older received in neurovascular consultation during the study period as well as their family caregivers.

\subsection{Inclusion Criteria}

In our study we included subjects: aged 60 years and over without distinction of sex able to answer the questionnaire who were consulted for stroke during the study period accompanied by a family member defined as primary caregiver who consented to the study.

\subsection{Non-inclusion Criteria}

The following were not included in our study:

Elderly subjects with an unconfirmed diagnosis of stroke

Elderly subjects with impaired consciousness

Family members who were not considered primary caregivers.

All those who did not give consent to participate in the study.

\subsection{Sampling}

\subsubsection{Type and Procedure of Sampling}

Sampling was based on exhaustive and systematic recruitment of patients who came to the neurovascular consultation for stroke during the study period. Each patient was therefore equally likely to be interviewed.

\subsubsection{Sample Size}

Our study included the 60 patients received during the study period who met the inclusion criteria.

\subsection{Variables of Interest}

\section{Classification of variables:}

1. Sociodemographics: age and sex of both patient and caregiver; marital status, address, and education level of patient; occupational status of patient and caregiver.

2. Clinical data: type of stroke, deficits, functional recovery and duration.

3. Direct care data, which will be captured here by direct non-medical costs that are attributable to treatment but relate to non-health resources such as transportation.

4. Indirect care data that capture the value of time spent by family members or other caregivers that is not considered part of the care provided by formal health care providers. Thus, it is these informal care costs that we are interested in because they reflect the financial assistance provided by the primary caregiver. Since this assistance can be valued using two methods (the opportunity approach and the replacement approach), we will restrict ourselves to data from the opportunity cost (OC) approach, which are those estimated using the value of the activity that caregivers forego in order to provide informal care. 
5. Out-of-home catering, fuel, and other unforeseen expenses are not included in our indirect costs.

6. MINI-ZARIT grid: evaluation of the suffering of informal caregivers in the home care of elderly people; grid made up of 5 items, the ratings being $0,0.5$ or 1 for a total score ranging from 0 to 7 . Between 0 and 1.5 the burden is absent or slight; between 1.5 and 3.5 the burden is slight to moderate; between 3.5 and 5.5 the burden is moderate to severe; between 5.5 and 7 the burden is severe.

7. The Geriatric Depression Scale in its short version (GDS): assesses the psychological impact of the disease on the patient; composed of 15 items scored from 0 to 1 ; the answer to each question being YES or NO; a score of 0 to 5 is normal; between 5 and 9 , the subject has a high probability of depression; from 10 onwards, the subject is almost always in depression.

\subsection{Collection Tools}

We used a survey form with 3 parts:

Patient, caregiver, illness and indirect burden data.

The ZARIT scale, which is a grid for evaluating the suffering of natural caregivers in the home care of the elderly

The Geriatric Depression Scale (GDS)

\subsection{Collection Procedure and Data Analysis}

After their neurovascular consultation, we completed a questionnaire with patients and caregivers meeting the inclusion criteria. The questions were asked face-to-face by the investigator, who was a final-year medical student, assisted when the language barrier required it, by a nursing assistant. The data were then entered into the statistical software.

The EPI-INFO version 3.5.4 program for Windows was used for data collection and analysis. This analysis focused on:

The evaluation of the financial cost including essentially 2 elements:

Estimation of the financial losses related to work stoppage: to do this, we estimated the daily earnings of the main caregiver, which we multiplied by the number of days lost due to the assistance provided to the elderly stroke victim; therefore, caregivers who are not employed and those working for the civil service with a fixed monthly salary are not concerned in this section. These caregivers have time off work and generally receive their salary without difficulty.

Travel costs: the aim was to estimate the expenses related to transport from home to the neurovascular consultation room, multiplied by the number of consultations made since the diagnosis of the disease. Thus, expenses related to travel for physical therapy sessions or for any other complementary examination were not taken into account.

Description of the socio-demographic characteristics of patients and their caregivers

The description of the clinical and psychological characteristics of the patients.

\section{Results}

\subsection{Sociodemographic Characteristics}

\subsubsection{In the Patients}

The mean age of our patients was 71.46 years (standard deviation 7.79 years).

The female sex predominated with a sex ratio of 0.71 .

Polygamous patients were more represented $(38.30 \%)$, followed by widowers (35\%), monogamous (18.3\%), divorced (5\%) and single (3.3\%).

The patients had studied Arabic for $38.30 \%$, illiterate for $31.70 \%, 8.30 \%$ have a higher level, $10 \%$ have secondary level and $11.6 \%$ have primary level.

Half of the patients were unemployed (see Table 1).

The majority of our patients had social security coverage; $48.3 \%$ were covered by the SESAME health scheme, $18.3 \%$ by IPRES (Senegal Institute for Pension Scheme) and 1.66\% by the FNR (National Fund for Pension Scheme).

Except for one, all our patients had a main caregiver, $98.30 \%$.

Table 1. Professional status of patients and caregivers.

\begin{tabular}{lllll}
\hline \multirow{2}{*}{ professional Status } & Patients & \multicolumn{2}{c}{ Caregiver } \\
\cline { 2 - 5 } & Number & Percentage (\%) & Number \\
\hline Employed & 17 & 28.30 & 34 & 1 \\
Retired & 10 & 16.70 & 21 & 57.60 \\
Unemployed & 33 & 55.00 & 3 & 1.70 \\
Other & 0 & 0 & 55.60 & 5.10 \\
Total & 60 & 100.00 & 59 & 100.00 \\
\hline
\end{tabular}

\subsubsection{For the Main Caregiver}

The majority of caregivers were women with a sex ratio of 0.84 ; they were mainly children of the patients $(66.6 \%)$, followed by spouses (15\%).

The average age of the caregivers was 42.64 years (standard deviation 11.78 years). The majority of main caregivers were women $(54.20 \%)$; the sex ratio was 0.84 .

More than half of the caregivers were employed (see Table 1).

\subsection{Clinical Characteristics of the Patients}

DALYs were overwhelmingly encountered at $98.30 \%$ and $1.7 \%$ were hemorrhagic.

The clinical manifestation of the stroke most frequently found in the acute phase in our patients was a hemi-corporeal motor deficit $(76.70 \%)$, followed by speech disorders such as dysarthria (23.30\%) and aphasia $(21.70 \%)$. 
The majority of our patients had recourse to physiotherapy, $36 \%$. The average number of physiotherapy sessions was 23.54 sessions (standard deviation 27.45 sessions). Among the patients with motor deficits, most had retained sequelae, i.e. $55.20 \%$. The average duration of functional recovery was 12.04 months (standard deviation 12.78 months).

\subsection{Psychological Impact}

For the majority of caregivers, the burden was mild to moderate $(45.80 \%)$.

The mean ZARIT score was 2.65 (standard deviation 1.52) with extremes of 0 and 5.5 .

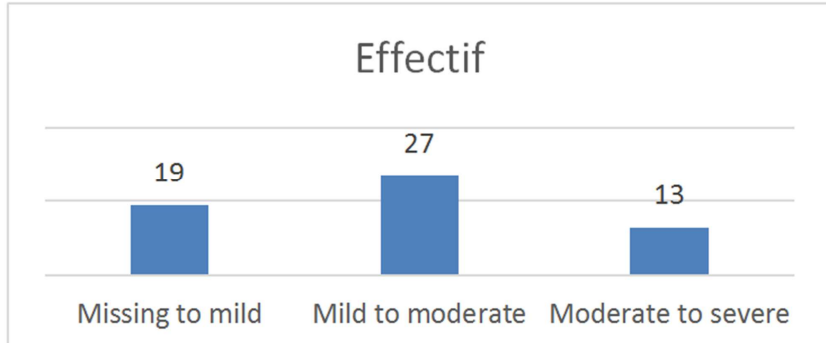

Figure 1. Psychological impact on the primary caregiver (MINI-ZARIT score).

There was a high probability of depression in $30 \%$ and $10 \%$ of patients were depressed.

The mean Geriatric Depression Scale was 5.26 (standard deviation 2.89) with extremes of 0 and 13 . The median was 4.5 .

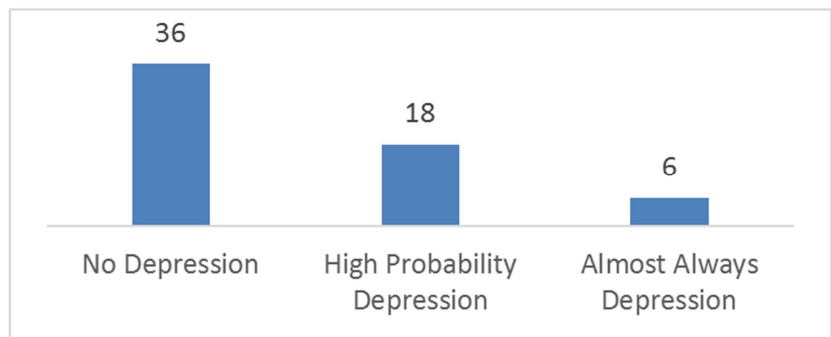

Figure 2. Psychological impact on the patient (Geriatric Depression Scale).

\subsection{Economic Impact}

The mean length of time the main caregiver was off work was 23.86 days (standard deviation 64.53 days) with extremes ranging from 0 to 365 days.

The average cost of financial loss related to the primary caregiver's time off work was \$200.38 (SD \$564.72). The majority of caregivers had almost no loss (69.5\%)

The average cost in travel expenses was $\$ 139.24$ (standard deviation \$321.03), with the maximum being $\$ 2,003.53$.

The average total cost was therefore $\$ 339.62$ (standard deviation $\$ 650.97$ ) with extremes ranging from $\$ 0$ to $\$ 3005.30$.

\section{Discussion and Comments}

\subsection{Limitations and Constraints}

We encountered several difficulties during our work:
The evaluation scores used are not adapted to the African context, which is very marked by taboos and the respect accorded to the elderly. This limitation does not affect the credibility of the results.

The language barrier: very few patients spoke French; as a result, the translation of certain terms in the GDS was quite difficult. The same was true for the ZARIT score with illiterate caregivers.

The caregivers' answers were very approximate on financial losses, travel expenses for physical therapy sessions, accommodation expenses for residents outside Dakar, and expenses related to meals outside the home. Thus they could not be evaluated.

\subsection{Socio-demographic and Clinical Characteristics}

\subsubsection{In Patients}

Our patients had an average age of 71.46 years (standard deviation 7.79 years) which corresponds to the average age of Aribi et al [5]. In our study, the most represented age group was 65-70 years and a small percentage of subjects over 85 years was noted. Yangatimbi et al found an average age of 70.02 years in their study on the epidemiology of DALY in the neurology department of FANN NUHC of in Dakar, and the most represented age group was $65-74$ years [6].

The majority were female $(58.30 \%)$ with a sex ratio of 0.71. Yangatimbi et al also found a female predominance, whereas several authors, notably in Spain, reported a male predominance $[6,7]$.

Most of our patients were married or widowed (91.60\%). The study on access to hospital care for stroke patients at FANN NUHC found that $90 \%$ of patients were married and Yangatimbi et al found that $70 \%$ were married $[6,8]$.

\subsubsection{Among Caregivers}

The descendants of the patients are the most represented, followed by the spouses, which is in line with the data in the literature. Indeed, Mpandzou et al found $44.50 \%$ of descendants, while Bucki et al found that the majority of the spouses of stroke patients were descendants.

We found that the majority of primary caregivers were women $(54.20 \%)$, for a sex ratio of 0.84 . Our results are in line with those of Bucki et al who found a majority of female caregivers [10].

The mean age of the main caregivers was 42.64 years (standard deviation 11.78 years). A similar result was found by Mpandzou et al with a mean age of 41.4 years (standard deviation 11.9 years) [9].

Among the primary caregivers, $57.60 \%$ were employed, mostly men. $35.60 \%$ were unemployed, the majority of whom were women. $5.10 \%$ designated as "other" were students, only men. And $1.70 \%$ were retired, mostly women. Bucki et al. also found that "more men were working" [10].

\subsection{Psychological Impact on the Patient and the Main Caregiver}

\subsubsection{Psychological Impact on Patients}

We found $30 \%$ of patients with a high probability of 
depression and $10 \%$ of patients who were almost always depressed, for a total of $40 \%$ of depression if we agree with the classification used by Aribi et al [5].

In the study conducted by Aribi et al, post-stroke depression was found in $27.50 \%$ of patients, of which $22.5 \%$ had a score of 6 to 9 on the GDS and 5\% had a score greater than or equal to 10 . This depression score is lower in his case probably due to the fact that his cohort was divided into two groups namely non-depressed patients $(\mathrm{GDS} \leq 5)$ and depressed patients (GDS $>5$ ) [5].

\subsubsection{Psychological Impact on the Main Caregiver}

The majority of caregivers $27(45.80 \%)$ had a mild to moderate burden; 19 (32.20\%) had no to mild burden and 13 $(22 \%)$ had a moderate to severe burden.

Mpandzou et al found a mean ZARIT score of 44.8 (standard deviation 10.6) at one month (corresponding to moderate burden) which decreased progressively at 3 and 6 months. This mean score seems higher in his case than in ours, which was 2.65 (standard deviation 1.52) (corresponding to mild to moderate burden). Although we both used the same burden inventory scale, the significant difference was in the version used. Mpandzou et al used the 22-item ZARIT (in which a score between 21 and 40 indicates a light burden; between 41 and 60, a moderate burden; a score above 60 , a severe burden). In view of these elements, we can therefore state that our results are fairly close to those they found.

\subsection{The Direct and Indirect Financial Burden}

The average duration of work stoppage for the main carers was 23.86 days (standard deviation 64.53 days).

In the literature review on indirect costs associated with stroke, Heesoo J et al include two main categories of indirect costs, namely lost productivity and the cost of informal care $[11,12]$. Thus, the annual indirect costs per stroke patient, represented in millions of US dollars, were in the range of 904-1,453 US dollars in Thailand in 2007 and 23,451 US dollars in the Netherlands in 2006.

The financial losses related to work stoppage in our study were 120,016.94 FCFA (standard deviation 338,237.34 FCFA) or 200.38 USD (standard deviation 564.72 \$USD).

The average travel cost was 83,396.61 FCFA (standard deviation 192,279.08 FCFA) or 139.24 USD (standard deviation 321.03 USD).

In the end, the average total indirect cost was 203,413.559 CFA francs (standard deviation 389,893.23 CFA francs) or 339.62 USD (standard deviation 650.97 USD). Our results are much lower than those found in the literature. This large difference can be explained by several factors:

First, the sample size. Our study included a total of 59 main caregivers, compared to the studies in Thailand and the Netherlands, which included 149 and 218 caregivers, respectively.

Second, the indirect cost estimate would be more related to travel costs, as this is the only data item of interest to virtually all caregivers. These travel expenses were in turn limited because they concerned only transportation to neurovascular appointments, and did not include travel to physiotherapy, laboratories, or for imaging examinations as part of the etiological assessment.

Afitap et al estimated that the indirect costs of lost productivity due to stroke in Turkey were US\$4,068.30 (standard deviation US\$4,432.86) [13]. These results are still higher than ours although their sample size is quite close to that of our study (84 patients).

The majority of studies on indirect costs found in the literature, notably those carried out in the United States and the United Kingdom, only consider productivity losses resulting from mortality and morbidity [14]. Indirect costs related to informal assistance are classified separately. The results show that in the United States in 2008, the total direct and indirect costs of stroke were estimated at $\$ 65.5$ billion, with $67 \%$ of these costs coming from direct costs and $33 \%$ from indirect costs (which do not take into account informal help). In the 27 countries of the European Union in 2008, the total annual cost of stroke was estimated at $\$ 27$ billion, of which $68.5 \%$ was for direct costs and $31.5 \%$ for indirect costs; a significant $\$ 11.1$ billion was obtained for the cost of informal assistance [15].

In a study conducted in Senegal in 2017, the average direct cost of stroke over a 3-month period was 450,716 FCFA (standard deviation 405,214 FCFA) or 752.52 USD (standard deviation 676.55 USD) [16]. This average cost is double that found in our study, 203,413.559 FCFA (standard deviation 389,893.23 FCFA) or 339.62 USD (standard deviation 650.97 USD). In view of this, we can affirm that although it is lower than the direct cost, the indirect cost remains quite high and therefore represents a heavy burden for a population the majority of which is unemployed.

\section{Conclusion and Recommendations}

The objective of our study was to evaluate the psychological, social, and economic aspects of stroke management in the elderly at the neuroscience clinic of FANN NUHC. More specifically, the aim was to evaluate the burden on the caregiver, the psychological impact on the patient in terms of depression, and to estimate the indirect cost of stroke in the elderly.

On the basis of the obtained results, our recommendations are: First, to clinicians who should:

Identify the primary caregiver of any patient diagnosed with stroke and offer psychological support.

Assess depression to optimize management.

Then to researchers who could do a study with a larger population.

Propose evaluation scales for caregiver burden and depression in the elderly that are better adapted to the African population in general and Senegalese in particular.

Finally, to the decision makers who could

Facilitate caregivers' access to psychological services and/or implement a neuropsychology training program for clinicians.

Provide lower cost home care services. 


\section{References}

[1] National agency for Statistics and demography. General Sensus of the population, habitat, Agriculture and breeding. https://www.ansd.sn/ressources/rapports/Rapport-definitifRGPHAE.

[2] World Health Organisation, Diet, Nutrition and Chronic Diseases Prevention: Report of a OMS / FAO experts consultation. Séries of technical reports 916. Geneva; 2003.

[3] Letaief M, El Mhamdi S, Nouira R, Mhirsi A, Sriha A, Belghith Z, et al. Mise en place et impact d'un programme d'assurance qualité pour l'hypertension artérielle en première ligne. Pratiques et Organisation des soins. 2010; 41 (1): 45-53.

[4] Touré K, Sawadogo AA, Sow A, Basse A, Diagne NS, Diop MS, et al. Mortalité des patients hospitalisés pour AVC ischémique en neurologie au CHU de FANN à Dakar. NPG Neurologie-Psychiatrie-Gériatrie. 2017; 17: 230-4.

[5] Aribi L, Baâti I, Damak M, Gaha L, Mhiri C, Amami O. Dépression après un accident vasculaire cérébral chez le sujet âgé: étude transversale à propos de 40 cas. L'information psychiatrique. 2013; 89 (10): 843-50.

[6] Yangatimbi E, Toure K, Ould MLS, Sow A, Diagne NS, Basse A, et al. Epidémiologie de l'AVC ischémique chez des patients âgés à la clinique neurologique du CHU de FANN, DakarSénégal. Journal de neurologie-neurochirurgie-psychiatrie. 2017; 002 (16): 27-34.

[7] Sene D, Basse AM, Ndiaye M, Toure K, Diop MS, Thiam A et al. Prise en charge des accidents vasculaires cérébraux au Sénégal. Rev neurol. 2007; 163: 8-9, 823-7.

[8] $\mathrm{Ba}$ A. Accessibilité aux soins hospitaliers des patients victimes d'un accident vasculaire cérébral au Sénégal: à propos de 100 cas vus au service de neurologie du CHNU de FANN-Dakar [Thèse]. Dakar: Université Cheikh Anta Diop; 2007. 174p.
[9] Mpandzou GA, Ngouma A, Ossou-nguiet PM, Nkounkou A, Motoula LDH, Sounga BEP. Evaluation de la charge de l'aidant après un accident vasculaire cérébral au centre hospitalier universitaire de Brazzaville. AJNS - African Journal of Neurological Sciences. 2018; 37 (1).

[10] Bucki B, Spitz E, Baumann M. Prendre soin des personnes après AVC: réactions émotionnelles des aidants informels hommes et femmes. 2012; 2 (24): 143-56.

[11] Heesoo J, Mary GG, Jing F, Guijing W. A littérature review of indirect costs associated with stroke. J Stroke Cerebrovasc Dis. 2014; $23 \quad$ (7): 1753-63. [DOI: 10.1016/j.jstrokecerebrovasdis.2014.02.017].

[12] Coûts directs et indirects [en ligne]. Lexeco [cité le 13 avril 2019]. Disponible sur: https://lexeco.wordpress.com/c/coutsdirects-et-indirects.

[13] Afitap I, Hatice ŞB, Erkan M, Yasemin Y, Sadiye M, Nilgün M. Economic burden of stroke. Turk J Phys Med Rehab. 2017; 63 (2): 155-9. [DOI: 10.5606/tftrd.2017.183].

[14] Saka Ö, McGuire A, Wolfe C. Cost of stroke in the United Kingdom. Age and Ageing [en ligne]. 2009 [cité le 02 décembre 2019], 38 (1): 27-32. Disponible sur: https://academic.oup.com/ageing/articleabstract/38/1/27/41534.

[15] Outils d'évaluation: prendre en compte la situation de l'entourage et des aidants [en ligne]. France: Novartis; [cité le 27 août 2019]. Disponible sur: https://www.proximologie.com/en-pratique/outils-devaluation.

[16] Nyassinde J. Evaluation du coût direct des accidents vasculaires cérébraux à la clinique de neurosciences du CHNU de FANN-Dakar [Mémoire]. Dakar: université Cheikh Anta Diop; 2017. 74p. 